\title{
Toxicological Impact of Pentachlorophenol on the Hepatic and Reproductive Activity of the Stinging Catfish Heteropneustes fossilis
}

\author{
Sonam Singh ${ }^{1}$, Radha Chaube ${ }^{1, *}$ \\ ${ }^{1}$ Department of Zoology, Institute of Science, Banaras Hindu University, Varanasi-221005, India.
}

\author{
Article History \\ Received October 9, 2019 \\ Accepted November 20, 2019 \\ First Online November 25, 2019

\section{Corresponding Author \\ Tel.: +9336847252 \\ E-mail: chauberadha@rediffmail.com}

\section{Keywords}

Gonadosomatic index

Hepatosomatic index

Steroid hormone

Cortisol

\begin{abstract}
Pentachlorophenol (PCP) is an organochlorine compound used widely as a pesticide, disinfectant, and biocide. Its $\mathrm{LC}_{50}$ was determined, which is $400 \mu \mathrm{g} \mathrm{L}^{-1}$ in a bioassay system, and toxicity was evaluated in female Heteropneustes fossilis exposed to $1 / 25^{\text {th }}$ $\left(16 \mu \mathrm{g} \mathrm{L}^{-1}\right)$ and $1 / 10^{\text {th }}\left(40 \mu \mathrm{g} \mathrm{L}^{-1}\right) \mathrm{LC}_{50}$ concentrations for 28 days in previtellogenic and late vitellogenic phases. Behavioural, metabolic and reproductive parameters were evaluated. The exposed fish were put to high stress judging from the significant increase in plasma cortisol and erratic behaviours. The body mass of the liver and ovary decreased significantly. Various histopathological anomalies were noticed in the liver and ovary and were attributed to altered steroid biosynthesis and metabolism judging from increased estradiol-17 $\beta$ and testosterone levels in plasma and their decreased levels in the ovary and liver. The results show that the toxicant can act at different levels to produce behavioural, physiological and pathological changes affecting metabolism and reproduction.
\end{abstract}

\section{Introduction}

Pentachlorophenol (PCP, CAS:87-86-5), is a typical and worldwide used an organic chlorinated compound for preserving utility poles, railroad, and crossties, and as insecticides, pesticides, and biocides for controlling agricultural and household pests (Copper \& Jones, 2008). It's contamination is of critical environmental concern due to toxicity and non-degradation. Its deleterious effects such as developmental toxicity, liver defects, genetic toxicity, and endocrine disrupting activity have been reported in humans, livestock and wildlife health (Morales et al., 2014). In fish species, PCP has been reported to cause DNA damage, endocrine disruption (Zhang, Zhang, Qi, Huang,\& Zhang, 2014), impairments of ovaries, follicular atresia, unique gene expression patterns (Sawle, Wit, Whale, \& Cossins, 2010), morphological deformities (Cheng, Ekker, \&
Chan, 2015), altered activities of antioxidant enzymes, changes in serum testosterone (Zhang et al., 2014), antiestrogenicity (Zhao et al., 2006), reproductive system damage (Zhang et al., 2014), immunotoxicity (Shelley, Balfry, Ross, \& Kennedy, 2009) and gene mutation (Yin, Zhu, Hu, \& Zhao, 2009). Endocrine disruption by PCP in fish was monitored in adult zebrafish and rare minnow (Gobiocypris rarus) showed elevated plasma thyroxine concentrations and decreased mRNA expression levels of tsh $B$ and trB in the brain (Zha, Wang, Wang, \& Ingersoll, 2007). In this species, the estrogen receptor (ER) mRNA was up-regulated in males and downregulated in females, and vitellogenin (Vtg) mRNA induction and serum vtg protein increase was reported in longer exposed (21 days) females (Zhang et al., 2014).

Fish is used widely as a bio-indicator of water pollution due to rapid responses with high sensitivity to changes in their usual physiological functions such as 
molecular, biochemical, cellular, hormonal, or behavioural responses (van der Oost, Beyer, \& Vermeulen, 2003). In toxicological studies, measurement of hormone levels, histological changes, gonadosomatic index (GSI) and hepatosomatic index (HSI) are often evaluated to determine environmental risks in fish health. The freshwater catfish Heteropneustes fossilis is an edible, economically important fish, and is ideal for wastewater aquaculture. To date, the toxicological impact of PCP was meager on this air-breathing catfish. The present study was to assess behavioural and histological alterations in the liver and ovary of $H$. fossilis in two different phases of the reproductive stages (resting and pre-spawning). These alterations were compared with changes in GSI and $\mathrm{HSI}$ as well as cortisol, estradiol-17 $\beta\left(E_{2}\right)$ and testosterone $(T)$ levels. The present study will be useful in understanding the PCP-triggered metabolic and reproductive dysfunctions encountered by freshwater fishes.

\section{Materials and Methods}

\section{Chemicals}

PCP (Crystalline, 99\% pure) was purchased from Acros organics (Geel, Belgium). Hormone assays were performed by specific ELISA kits from Dia Metra (Giustozzi, Foligno, PG Italy) for $E_{2}$ (REF-DKO003, LOT4511A) and testosterone (REF-DKO002, LOT-4510A). All other chemicals were of analytical grade and purchased locally.

\section{Animals and Experimental Design}

All experiments were performed by following the guidelines of the Animal Ethics Committee of Banaras Hindu University, Varanasi (F.Sc./IAEC/2016-17/113S), as well as national guidelines for experimentation in animals and all care was taken to prevent cruelty of any kind. In this study, sexually mature adult female catfish Heteropneustes fossilis weighing (40-50g) were collected from the local fish market during previtellogenic (resting; January: GSI:1.12\%; 10L:14D;18 $\pm 2^{\circ} \mathrm{C}$ ) and late-vitellogenic (pre-spawning; May: GSI:4.23\%; $13 \mathrm{~L}: 11 \mathrm{D} ; 28 \pm 2{ }^{\circ} \mathrm{C}$ ) phases of the annual reproductive cycle. The fish were disinfected with $0.1 \%$ $\mathrm{KMNO}_{4}$ (for three days) and then were acclimatized in 20-L flow-through aquarium tanks under regular photoperiod and ambient temperature for two weeks and were fed daily with minced goat liver ad libitum during acclimatization and course of the experiment.

PCP was dissolved in ethanol and then diluted with water to obtain the required concentration. The test concentrations (100-800 ppm) were chosen based on pilot experiments, to determine the $\mathrm{LC}_{50}$. The $\mathrm{LC}_{50}$ was determined according to the arithmetic method of Karber (Dede \& Kaglo, 2001). During the toxicity test, the fish was not fed. The mortality rate was determined at the end of 24, 48, 72 and $96 \mathrm{~h}$. The number of dead fish per group were recorded against the time of their death in a tabular form (Dede \& Kaglo, 2001). The data were used to calculate $\left.L C_{50}\right)$.

In each reproductive phase, acclimatized fish $(\mathrm{N}=10$ per group) was maintained in three different tanks of 10-L water capacity. Group 1 was control, group 2 was low dose PCP $\left(16 \mu \mathrm{L} \mathrm{L}^{-1} ; 1 / 25^{\text {th }}\right.$ of $\left.\mathrm{LC}_{50}\right)$ and group 3 was high dose PCP $\left(40 \mu \mathrm{L} \mathrm{L}^{-1} ; 1 / 10^{\text {th }}\right.$ of $\left.\mathrm{LC}_{50}\right)$. During the exposure, the mortality and behaviour of the fish were monitored. The behavioural pattern was observed regularly and recorded (Kumari, Singh, Khanna, \& Sharma, 1997). The fish were exposed for 28 days. After completion of the experiment, blood was collected by a caudal puncture for hormone assays. Plasma was separated and stored at $-20^{\circ} \mathrm{C}$ till the test. The fish were weighed and sacrificed by decapitation. The liver and ovaries were dissected out, weighed, fixed in Bouin's fluid and stored in $70 \%$ alcohol.

The GSI was calculated as GSI (\%) =Weight of the gonad/Weight of the fish $X 100$

The HSI was calculated as HSI (\%) = Weight of the liver/ Weight of the fish $\times 100$

The Bouin's fluid tissues were processed for histology. Five $\mu \mathrm{m}$ paraffin sections were stained with hematoxylin and eosin routinely. Micrographs were taken by using a Leica DM LS microscope equipped with a Leica DFC310 FX camera (Leica DM2000 LED, Germany). The histological alterations were described by using a method (Bernet, Schmidt, Meier, BurkhardtHolm \& Wahli, 1999).

Steroid extraction from plasma and tissues were described previously (Chaube, Mishra, \& Singh, 2010). $E_{2}, T$, and cortisol (F) levels were estimated by enzymelinked immunosorbent assays (ELISA), following the manufacturer's instructions (Chaube et al., 2010). Optical density was read at $450 \mathrm{~nm}$ using iMark $^{\mathrm{TM}}$ Microplate Absorbance Reader (BioRad, USA) and the concentration was expressed as $\mathrm{ng} / \mathrm{mL}$ or $\mathrm{ng} / \mathrm{g}$. The intra-assay coefficients of variance for $E_{2}, T$, and $F$ were found to be $\leq 9.3 \%, \leq 7 \%, \leq 8.9 \%$, respectively.

\section{Statistical Analysis}

Data were analyzed through a one-way analysis of variance (ANOVA) followed by post hoc test, Tukey's multiple range test $(P<0.05)$. Data were expressed as mean \pm standard error mean $(\mathrm{SEM})(\mathrm{N}=5)$. All the statistical analyses were performed in SPSS16 software (SPSS Inc., Chicago, IL, USA).

\section{Results \& Discussion}

The 96-h LC50 of PCP for the catfish $H$. fossilis was calculated to be $400 \mathrm{\mu gL}^{-1}$ (Farah, Ateeq, Ali, Sabir, \& Ahmad, 2004). The fish exposed to PCP exhibited aberrant behaviors like erratic swimming, loss of 
equilibrium and direction. The exposed fish moved to the surface more often than the control fish. Mucus was secreted excessively, and feeding decreased with time and dose. Later on, the fish were lethargic. Summary of the different behavioural changes is presented in Table 1. The responses were higher in the pre-spawning phase in comparison to the resting phase. There were highly significant increases in cortisol levels with respect to the concentration and season $(P<0.05)$.

The PCP exposure decreased the HSI (Cont $=1.25 \pm 0.01 ; \quad 16 \mu \mathrm{gL}^{-1}=1.18 \pm 0.01 ; \quad 40 \mu \mathrm{gL}^{-1}=1.04 \pm$ 0.01 -Resting phase; Cont $=1.7 \pm 0.01 ; 16 \mu \mathrm{gL}^{-1}=1.5 \pm 0.1$; $40 \mu \mathrm{gL}^{-1}=1.15 \pm 0.001$-pre-spawning phase $\mathrm{P}<0.001$, oneway ANOVA) and GSI (Cont $=1.12 \pm 0.01 ; 16 \mu \mathrm{gL}^{-1}=1.08 \pm$ $0.01 ; 40 \mu \mathrm{gL}^{-1}=0.9 \pm 0.1$-Resting phase; Cont $=4.23 \pm 0.01$; $16 \mu \mathrm{gL}^{-1}=3.5 \pm 0.1 ; \quad 40 \mu \mathrm{gL}^{-1}=3.01 \pm 0.01$-pre-spawning $\mathrm{P}<0.001)$ significantly in a concentration and seasondependent manner. Both the concentrations decreased the values in the pre-spawning phase but only the higher concentration decreased the values in the resting phase ( $\mathrm{P}<0.05$, Tukey's test)

The fish exposed to low dose $\left(16 \mu \mathrm{g} \mathrm{L}^{-1}\right)$ shifting of the nucleus towards the lateral region, the fusion of cell, fibrosis of blood vessel and degeneration of Kuffer cells (Figure 1). These changes were more conspicuous in the liver of the catfish exposed to the high dose $\left(40 \mu \mathrm{g} \mathrm{L}^{-1}\right)$ with greater leukocyte infiltration into the liver parenchyma especially around blood vessels.

In the resting phase, the ovary was filled with small immature and maturing follicles (Table 2). In comparison to the control, the PCP treatment, caused atretic changes in maturing follicles, degeneration of egg envelope and thinning of the ovarian wall. In the high dose $\left(40 \mu \mathrm{g} \mathrm{L}^{-1}\right)$ group, the number of atretic follicles increased, followed by oolysis and shrinkage of oocytes resulting in large interfollicular spaces.

In the pre-spawning phase, the changes were much more prominent (Table 2$)$. In the low dose (16 $\mu \mathrm{g}$ $\left.\mathrm{L}^{-1}\right)$ group, retraction of granulosa cells, increase in inter- follicular space, increase in atretic follicles, development of intra-follicular space in oocytes, dissolution of oocyte wall and folding of the ovarian wall were observed. In the high dose group $\left(40 \mu \mathrm{g} \mathrm{L}^{-1}\right)$, the changes were greater with changes of the disintegration of granulosa cells, rupture of granulosa layer, vacuolization in the cytoplasm of the vitellogenic oocytes, dissolution of yolk globules, damage to yolk vesicle and clumping of the cytoplasm of maturing oocytes.

The plasma, ovary, and liver estradiol-17 $\beta\left(E_{2}\right)$ levels showed significant changes in the PCP-exposed fish as compared to the control in the resting $(P<0.001$, one-way ANOVA; Figure 2A) and pre-spawning $(P<0.001$, one-way ANOVA; Figure $2 B)$ phases. There was a significant increase in plasma $E_{2}$ level in the 16 and $40 \mu \mathrm{g} \mathrm{L}^{-1}$ groups in both the phases $(\mathrm{P}<0.05$; Tukey's test). In the ovary and liver, the $E_{2}$ level decreased dosedependently $(\mathrm{P}<0.05)$.

Testosterone ( $T$ ) levels showed an overall significant effect in the $\mathrm{PCP}$ - exposed fish in the resting $(P<0.001$, one-way ANOVA, $F=11.08$; Figure $3 A$ ) and prespawning $(P<0.001$, one-way ANOVA, $F=17.42$; Figure $3 B)$ phases. There was a significant increase in plasma $T$ levels in the 16 and $40 \mu \mathrm{L} \mathrm{L}^{-1}$ PCP groups in both phases $(P<0.05$; Tukey's test). In the pre-spawning phase, the increase was 2 -folds in the $16 \mu \mathrm{g} \mathrm{L}^{-1}$ group and about 8 times more in the $40 \mu \mathrm{g} \mathrm{L}^{-1}$ group. The T level in the ovary and liver decreased dose-dependently $(P<0.05)$.

$\mathrm{LC}_{50}$ analysis permits to determine the tolerance limit of the species to various xenobiotics. Adult fish show different levels of tolerance to chlorophenols (Ge et al., 2017). When exposed to PCP, small scale yellowfin (Plagiognathops microlepis) was found more sensitive than black carp (Mylopharyngdon piceus) or cutler fish (Cutler alburnus) (Jin, Zha, Xu, Giesy \& Wang, 2012). The sensitivity for zebrafish varies between 130-196 $\mu \mathrm{g} \mathrm{L}^{-1}$ (Yin, Gu, Li, Wang \& Zhao, 2006). In our study, the LC50 value for $H$. fossilis was lower $\left(400 \mu \mathrm{g} \mathrm{mL}^{-1}\right)$ than that (580 $\mathrm{g} \mathrm{m} \mathrm{m}^{-1}$ ) (Farah, Ateeq, Ali, Sabir, \& Ahmad, 2004).

Table 1. Effects of PCP on the behaviour of catfish, Heteropneustes fossilis during the resting and pre-spawning phase of the reproductive cycle

\begin{tabular}{|c|c|c|c|}
\hline Parameters & Control & PCP (16 $\left.\mu \mathrm{g} \mathrm{L}^{-1}\right)$ & PCP $\left(40 \mu \mathrm{g} \mathrm{L}^{-1}\right)$ \\
\hline \multicolumn{4}{|l|}{ Resting Phase } \\
\hline Hyperactivity & - & + & ++ \\
\hline Loss of equilibrium & - & - & + \\
\hline Feeding behaviour & +++ & +++ & ++ \\
\hline Mucus covering & + & + & ++ \\
\hline Swimming capacity & ++ & ++ & ++ \\
\hline Plasma Cortisol (ng mL-1) & $5.65 \pm 0.01$ & $16.14 \pm 0.05^{a}$ & $35.18 \pm 0.02^{b}$ \\
\hline \multicolumn{4}{|l|}{ Pre-spawning Phase } \\
\hline Hyperactivity & - & ++ & +++ \\
\hline Loss of equilibrium & - & + & ++ \\
\hline Feeding behavior & +++ & ++ & + \\
\hline Mucus covering & + & ++ & +++ \\
\hline Swimming capacity & +++ & ++ & + \\
\hline Plasma Cortisol (ng mL ${ }^{-1}$ ) & $28.42 \pm 0.02$ & $84.36 \pm 0.01^{a}$ & $148.17 \pm 0.03^{b}$ \\
\hline
\end{tabular}

$(-)$ None, $(+)$ mild, $(++)$ moderate, $(+++)$ strong. 


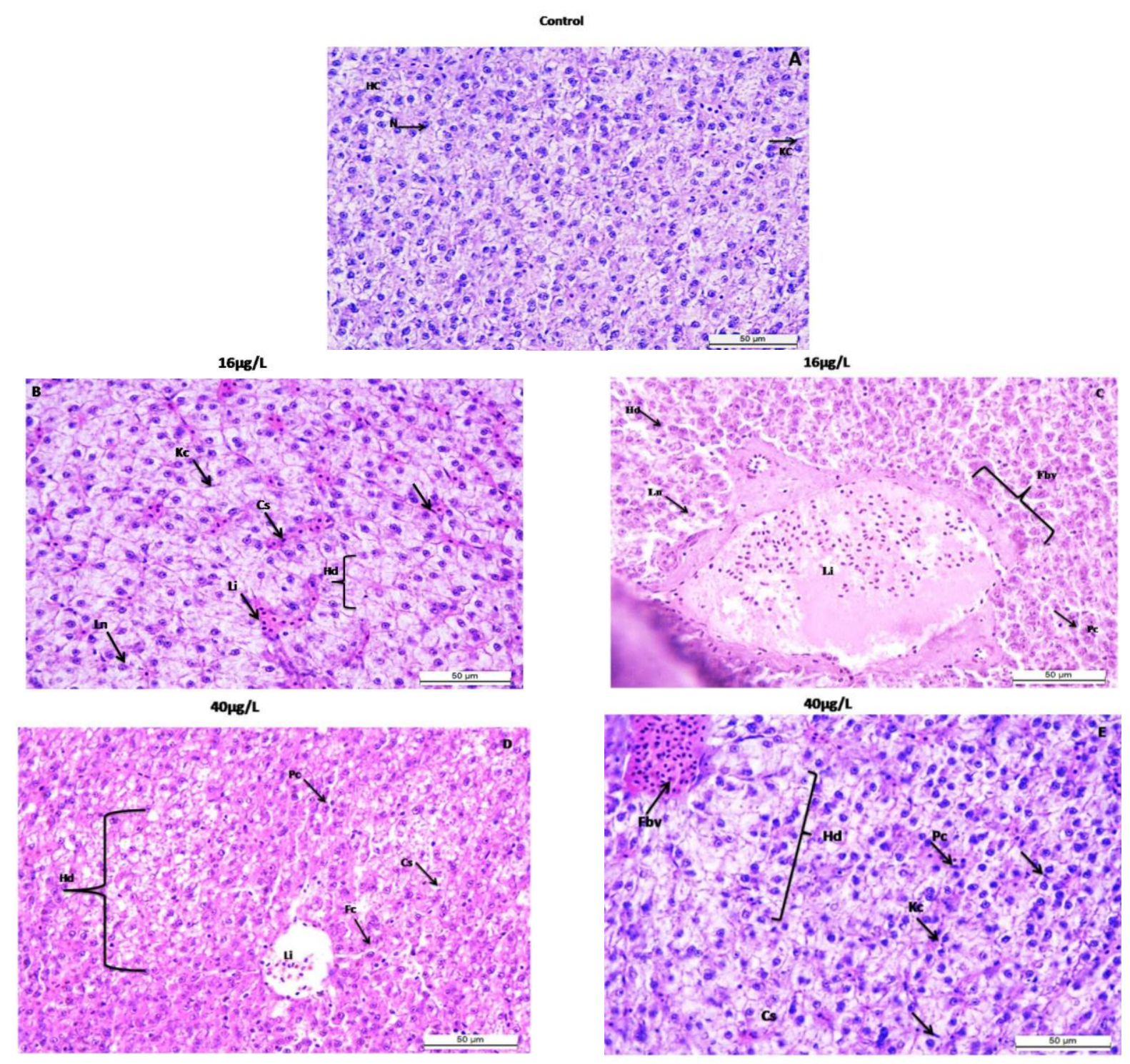

Figure 1. Histopathological alterations in the liver of $H$. fossilis (A) Parenchymal architecture of hepatocytes in the control group with centrally placed nuclei, (B and C) Fibrosis in blood vessel, fusion of cell, increase in number of kuffer cell and pycnotic cell, (D and E) leukocyte infiltration into liver parenchyma and especially around blood vessels as well as lateral shifting of the nuclei. LnLateral nuclei, Hd-Hepatocyte degeneration, Kc-Kuffer cell, Cs- Congestion of sinusoids, Pc-Pycnotic cell, Li-Leukocyte infiltration, Fc-Fusion of hepatocyte cell, Fbv-Fibrosis in the blood vessel (HE-40X).

Table 2. Effects of PCP on ovary and its follicle development during resting and pre-spawning phases of the reproductive cycle (table generated after visualization of histological images)

\begin{tabular}{|c|c|c|c|}
\hline Parameters & Control & $16 \mu \mathrm{g} / \mathrm{L}$ & $40 \mu \mathrm{g} / \mathrm{L}$ \\
\hline \multicolumn{4}{|l|}{ Resting Phase } \\
\hline Interfollicular Space & + & ++ & +++++ \\
\hline Thining of ovarian wall & - & ++ & ++++ \\
\hline Atretic cell & + & ++ & +++++ \\
\hline \multicolumn{4}{|l|}{ Pre-spawning Phase } \\
\hline Follicular epithelium & Separated & Joined & Fused \\
\hline Follicular epithelium nuclei & Uninucleated & Binucleated & Multinucleated \\
\hline Interfollicular Space & + & ++ & +++ \\
\hline Interafollicular Space & + & ++ & +++ \\
\hline Yolk granules & Order & Order & Dissoluted \\
\hline
\end{tabular}

(-) None, (+) mild, (++) moderate, (+++++) strong. 


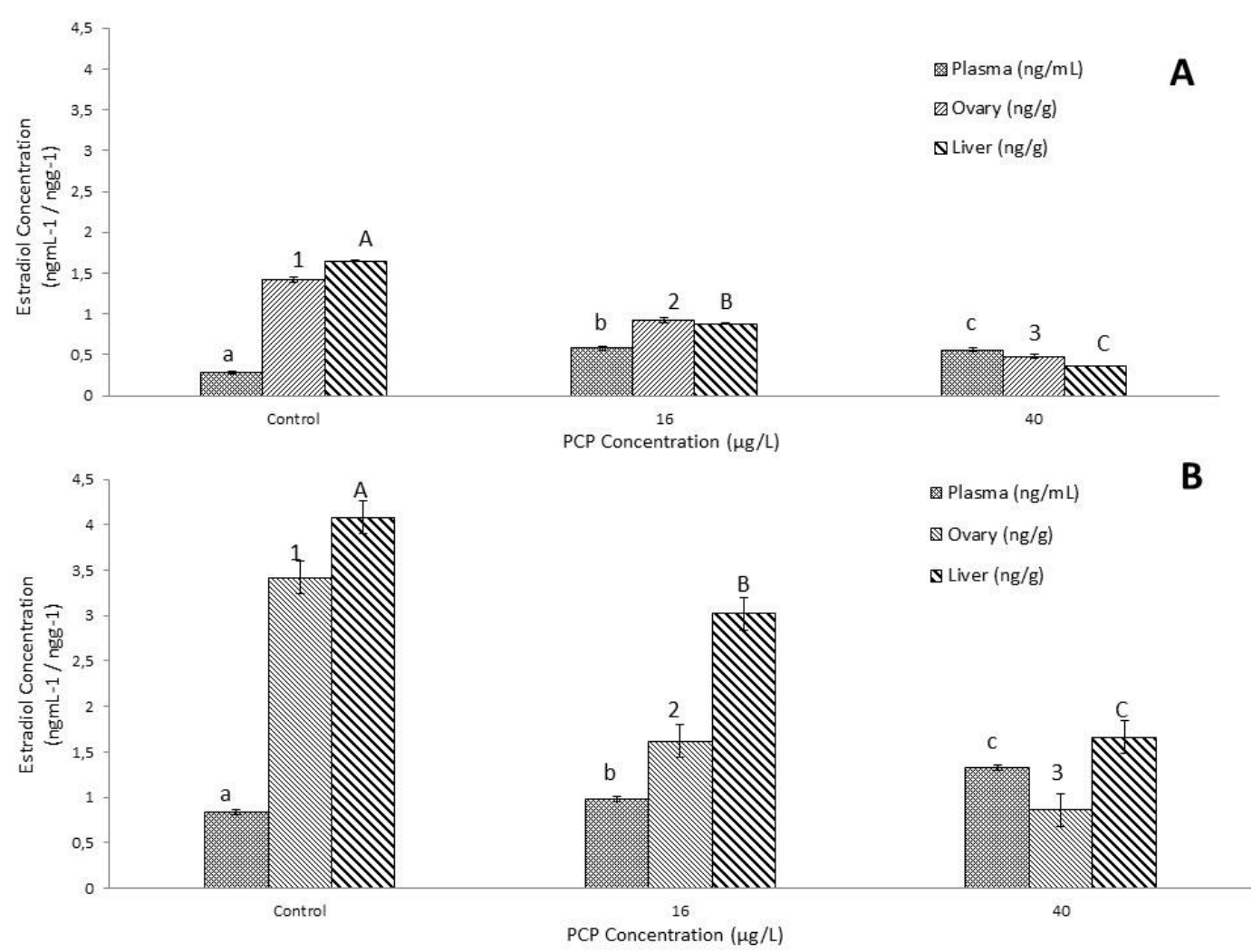

Figure 2. Changes in estradiol-17 $\beta$ in the ovary, liver, and plasma after exposure to $P C P$ in resting $(A)$ and pre-spawning (B) phases. Data were expressed as mean \pm SEM $(n=5)$. Data were analyzed by one-way ANOVA $(P<0.001)$, followed by Turkey's test $P<0.05)$. Different letters and numbers denote significant changes from the control $(P<0.05)$.
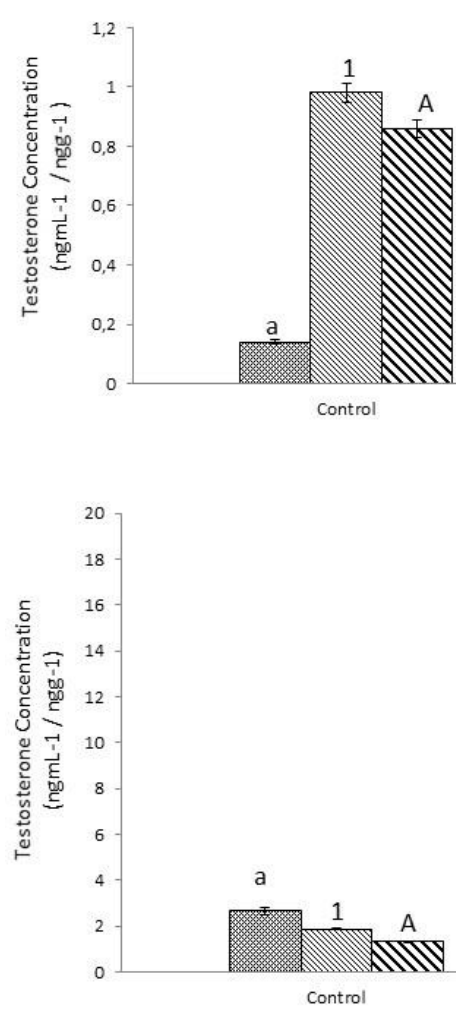

Resting phase

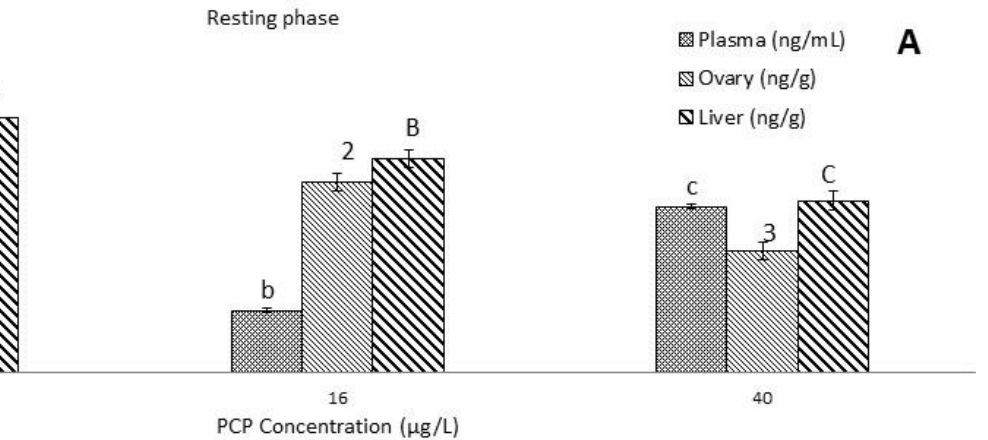

PCP Concentration $(\mu \mathrm{g} / \mathrm{L})$

Pre-spawning phase

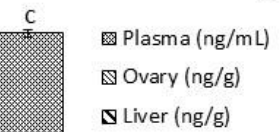

$\mathbf{v}$ Liver (ng/g)

40

Figure 3. Changes in testosterone levels in the ovary, liver, and plasma after exposure to $P C P$ in resting (A) and pre-spawning (B) phases. Data were expressed as mean $\pm \operatorname{SEM}(n=5)$. Data were analyzed by one-way ANOVA (P<0.001), followed by Turkey's test $P<0.05)$. Different letters and numbers denote significant changes from the control $(P<0.05)$. 
Farah et al. (2004) also reported lower sensitivity for murrel fish (Channa punctatus, $770 \mu \mathrm{g} \mathrm{L}^{-1}$ ) and higher sensitivity for walking catfish (Clarias batrachus, $640 \mu \mathrm{g}$ $\left.\mathrm{L}^{-1}\right)$. The differences in the $\mathrm{LC}_{50}$ value are influenced by the habit and habitat of the species.

The fish exposed to the sublethal concentrations of PCP elicited abnormal behaviors in the form of erratic swimming and loss of equilibrium. They become lethargic and mucus was secreted excessively. The intensity of mucus release increased with the dose of PCP. The abnormal behavior was more evident in the pre-spawning phase in the high dose group. The behavioural changes were attributed to oxidative stress induced by PCP (Ge et al., 2017). The cortisol data show that the stress endocrine axis was activated and the activation was more severe in the pre-spawning phase. Thus, there appears to be an association between the PCP-induced aberrant behaviors and stress responses.

The PCP exposure of the catfish resulted in a decrease of the GSI, as has been reported in Oreochromis niloticus, Chrysicthys nigrodigitatus and Clarias gariepinus (Hanson, Dodoo, Essumang, Blay, \& Yankson, 2007), Oryzias latipes and Gobicypris rarus (Zha et al., 2007). The GSI is a marker of gonadal growth and development. For example, exposure of Gobiocypris rarus to $\mathrm{PCP}\left(5 \mathrm{~g} \mathrm{~L}^{-1}\right)$ for 28 days induced severe degeneration and impairment of ovaries as well as follicular atresia (Zha et al., 2007). The treatment of male Oryzias latipes with PCP (20 $\mathrm{g} \mathrm{L}^{-1}$ for 28 days) induced the formation of testis-ova (Zha et al., 2007). Ovarian growth is controlled by steroids secreted under the influence of gonadotropins. The PCP exposure led to an impairment of steroidogenesis in the ovary of the catfish. The ovarian $E_{2}$ level decreased significantly in a dose-dependent manner. Likewise, the ovarian level of $T$ also decreased, suggesting that the steroid metabolism was adversely affected proximal to $T$ synthesis.

The liver is the main metabolic organ and the main site for steroid hormone inactivation. The hepatic level of $E_{2}$ and $T$ decreased significantly after the PCP exposure. These changes were conspicuous in the prespawning phase since steroid production is low in the gonad inactive phase (resting phase). At the same time, plasma levels of the steroids increased, suggesting an impairment of steroid transport from the blood to the liver. There was a high build-up of plasma T in the PCP exposed fish, especially in the high dose group in the pre-spawning phase. This may be due to the increased release of $\mathrm{T}$ from the ovary or decreased clearance of $\mathrm{T}$ to the liver for inactivation. The decrease in ovarian $E_{2}$ levels may be due to inhibited $\mathrm{T}$ aromatization. The liver is concerned with the synthesis of the yolk-precursor protein vitellogenin under $E_{2}$ stimulation in the prespawning phase. The low production of $E_{2}$, its mobilization to the liver and the low level of hepatic $E_{2}$ might have led to the decrease in hepatic mass and hence the decreased HSI. Degenerative changes in hepatocytes, leucocyte infiltration and clogging of blood capillaries (data not shown) also affected liver function. Since estrogens are held to be protective to cells and tissues (Zhang et al., 2014), the low $\mathrm{E}_{2}$ titer might have accentuated the tissue damage through oxidative stress. The low production of vitellogenin might have adversely affected ovarian growth indirectly. The exposure of the catfish to PCP induced abnormal behaviors and activation of the endocrine stress axis. The exposure led to impairment of biosynthesis and clearance and transport of ovarian $E_{2}$ and $T$, affecting adversely the ovarian-liver functions.

\section{Conclusion}

In this study, PCP act as a potent endocrine disruptor by modulating steroid hormone levels in plasma, ovary, and liver in a concentration and season dependent manner. We also observed changes in behavioural response. The histopathological study further revealed impairment in tissues under PCP exposure.

\section{Acknowledgements}

We declare that we have no conflicts of interest. This work was supported by the UGC-CAS and DSTPURSE schemes to the Department of Zoology (RC). S.S. is grateful to CSIR, New Delhi for the award of a Junior Research Fellowship.

\section{References}

Bernet, D., Schmidt, H., Meier, W., Burkhardt-Holm, P., \& Wahli, T. (1999). Histopathology in fish: proposal for a protocol to assess aquatic pollution. Journal of Fish Diseases, 22(1), 25-34. https://dx.doi.org/10.1046/j.1365-2761.1999.00134.x

Chaube, R., Mishra, S., \& Singh, R.K. (2010). In vitro effects of lead nitrate on steroid profilesin the postvitellogenic ovary of the catfish Heteropneustes fossilis. Toxicology in Vitro, 24(7), 1899-1904.

https://dx.doi.org/10.1016/j.tiv.2010.07.021

Cheng, Y., Ekker, M., \& Chan, H. (2015). Relative developmental toxicities of pentachloroanisole and pentachlorophenol in a zebrafish model (Danio rerio). Ecotoxicology \& Environmental Safety, 112, 7-14. https://dx.doi.org/ 10.1016/j.ecoenv.2014.10.004

Cooper, G.S., \& Jones, S. (2008). Pentachlorophenol and cancer risk: focusing the lens on specific Chlorophenols and contaminants. Environmental Health Perspectives, 116, 1001-1008.https://dx.doi.org: 10.1289/ehp.11081

Dede, E.B., \& Kaglo, H.D. (2001) Aqua-toxicological effects of water soluble fractions (WSF) of diesel fuel on O. niloticus fingerlings. Journal of Applied Sciences and Environmental Management, 5, 93-96. https://dx.doi.org/10.4314/jasem.v5i1.54965

Farah, M., Ateeq, B., Ali, M., Sabir, R., \& Ahmad, W. (2004). Studies on lethal concentrations and toxicity stress of 
some xenobiotics on aquatic organisms. Chemosphere, $55,257-265$

https://dx.doi.org/10.1016/j.chemosphere.2003.10.063

Ge, T., Han, J., Qi, Y., Gu, X., Ma, L., Zhang, C., ... Huang, D. (2017). The toxic effects of chlorophenols and associated mechanisms in fish. Aquatic Toxicology, 184, 78-93. https://dx.doi.org /10.1016/j.aquatox.2017.01.005

Hanson, R., Dodoo, D.K., Essumang, D.K., Blay, J., \& Yankson, K. (2007). The effect of some selected pesticides on the growth and reproduction of fresh water Oreochromis niloticus, Chrysicthysnigrodigitatus and Clarias gariepinus. Bulletin of Environmental Contamination \& Toxicology, 79, 544-547. https://dx.doi.org/10.1007/s00128-007-9279-3.

Jin, X., Zha, J., Xu, Y., Giesy, J., \& Wang, Z. (2012). Toxicity of pentachlorophenol to native aquatic species in the Yangtze River. Environmental Science and Pollution Research, 19, 609-618. https://dx.doi.org/ 10.1007/s11356-011-0594-1

Kumari, R., Singh, R.K., Khanna, Y.P., \& Sharma, B. (1997) Carbofuran induced stress mediated syndromes in Clarias batrachus. Proceedings of International Conference on Industrial Pollution Control Technology (pp. 113-119). India.

Morales, M., Martínez-Paz, P., Martín, R., Planelló, R., Urien, J., Martínez-Guitarte, J.L., \& Morcillo, G. (2014). Transcriptional changes induced by in vivo exposure to pentachlorophenol (PCP) in Chironomus riparius (Diptera) aquatic larvae. Aquatic Toxicology, 157, 1-9. http://dx.doi.org/10.1016/j.aquatox.2014.09.009

Sawle, A.D., Wit, E., Whale, G., \& Cossins, A.R. (2010). An information-rich alternative, chemicals testing strategy using a high definition toxicogenomics and zebrafish (Danio rerio) embryos. Toxicological Sciences, 118, 128139.https://dx.doi.org/10.1093/toxsci/kfq237

Shelley, L., Balfry, S., Ross, P., \& Kennedy, C. (2009). Immunotoxicological effects of a sub-chronic exposure to selected current-use pesticides in rainbow trout (Oncorhynchus mykiss). Aquatic Toxicology, 92, 95103.https:/dx./doi.org/10.1016/j.aquatox.2009.01.005

Van der Oost, R., Beyer, J., \& Vermeulen, N.P. (2003). Fish bioaccumulation and biomarkers in environmental risk assessment: a review. Environmental Toxicology \&Pharmacology, 13(2), 57-149.

https://dx.doi.org/10.1016/S1382-6689(02)00126-6

Yin, D., Zhu, H., Hu, P., \& Zhao, Q. (2009). Genotoxic effect of 2, 4, 6-trichlorophenol on P53 gene in zebrafish liver. Environmental Toxicology \& Chemistry, 28, 603608.https://dx.doi.org/10.1897/08-317.1

Yin, D., Gu, Y., Li, Y., Wang, X., \& Zhao, Q. (2006). Pentachlorophenol treatment in vivo elevates point mutation rate in zebrafish p53 gene. Mutation ResearchGenetic Toxicology \& Environmental Mutagenesis, 609, 92-101.

https://dx.doi.org/10.1016/j.mrgentox.2006.06.025

Zha, J., Wang, Z., Wang, N., \& Ingersoll, C. (2007). Histological alternation and vitellogenin induction in adult rare minnow (Gobiocypris rarus) after exposure tethynylestradiol and nonylphenol. Chemosphere, 66, 488-495.

https://dx.doi.org/10.1016/j.chemosphere.2006.05.071

Zhao, B., Yang, J., Liu, Z., Xu, Z., Qiu, Y., \& Sheng, G. (2006). Joint anti-estrogenic effects of PCP and TCDD in primary cultures of juvenile goldfish hepatocytes using vitellogenin as a biomarker. Chemosphere, 65, 359364.https://dx.doi.org/10.1016/j.chemosphere.2006.02 .019

Zhang, X., Zhang, X., Qi, Y., Huang, D., \& Zhang, Y. (2014). 2, 4dichlorophenol induces ER stress-mediated apoptosis via elF2 dephosphorylation in vitro. Environmental Toxicology, 31, 245-255. https://dx.doi.org/10.1002/tox.22039 